\title{
Erratum
}

\section{Disorganized attachment in adolescence: Emotional and physiological dysregulation during the Friends and Family Interview and a conflict interaction - Erratum}

\author{
Alessandro Decarli, Blaise Pierrehumbert, André Schulz, Violetta Katharina Schaan and Claus Vögele
}

doi: 10.1017/S0954579420001352. Published by Cambridge University Press, 22 December 2020

As a result of a production error, in Decarli et al. 2020, figures 3 and 4 , referenced in the text as online supplementary material, in fact also appear in the main article.

\section{Reference}

Decarli, A., Pierrehumbert, B., Schulz, A., Schaan, V.K., \& Vögele C. Disorganized attachment in adolescence: Emotional and physiological dysregulation during the Friends and Family Interview and a conflict interaction. Development and Psychopathology. Published online 22 December 2020. https://doi.org/10.1017/S0954579420001352

The publisher regrets this error. 